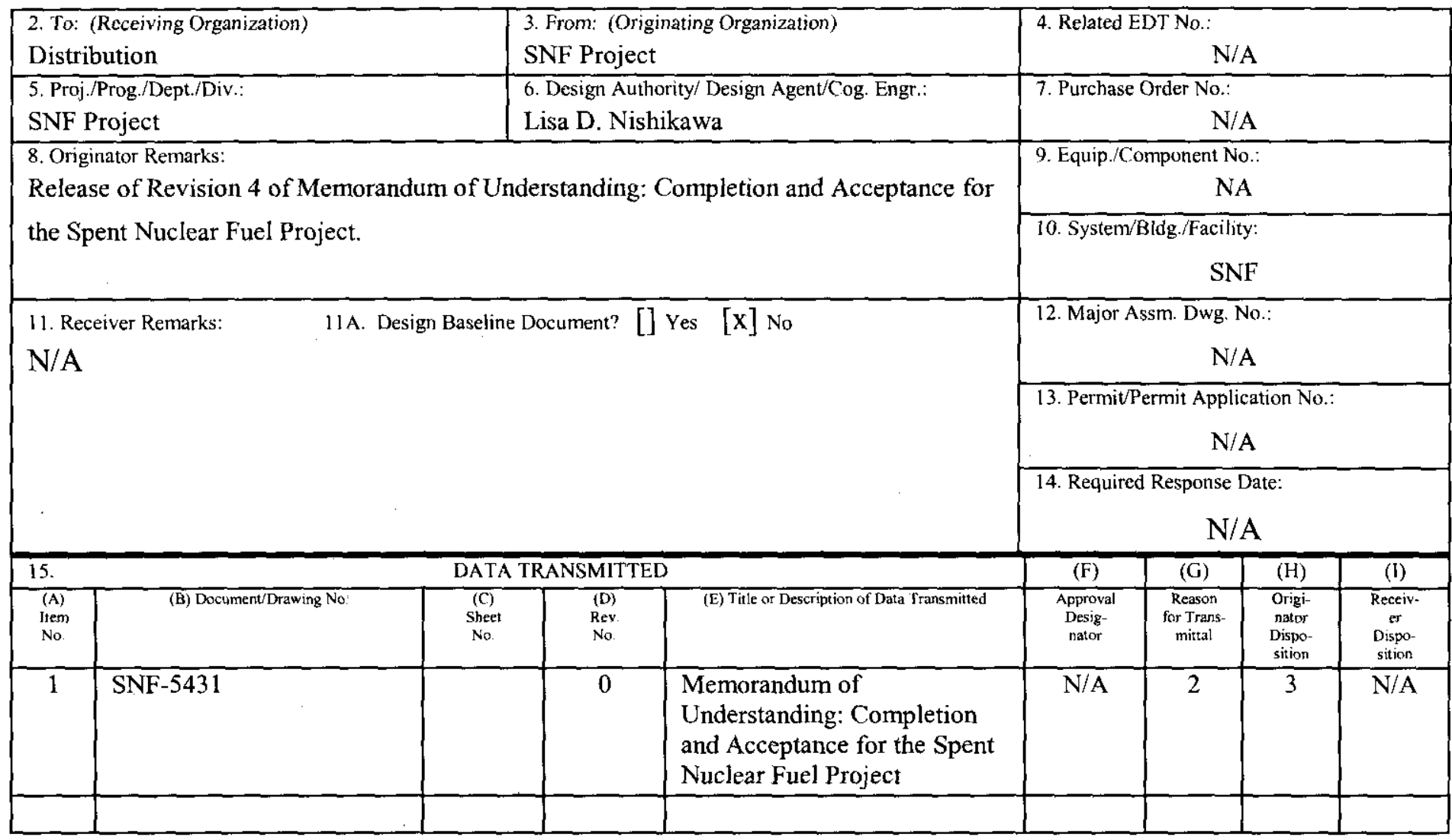

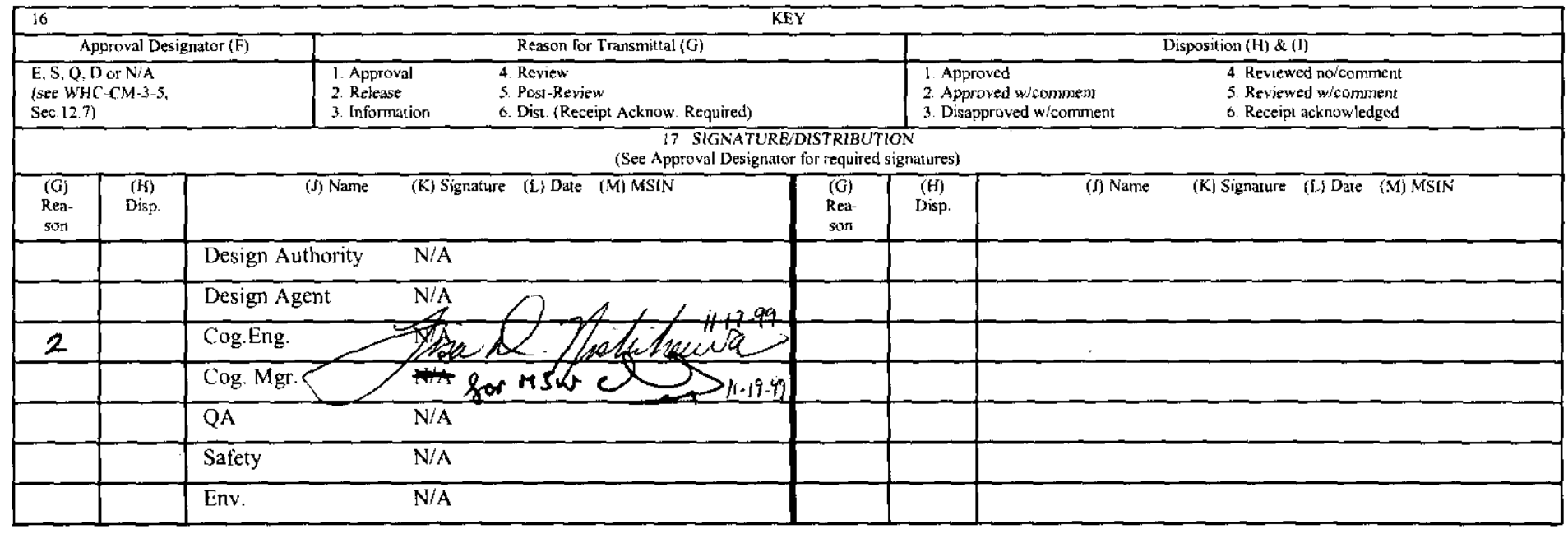

\begin{tabular}{|c|c|c|c|c|}
\hline 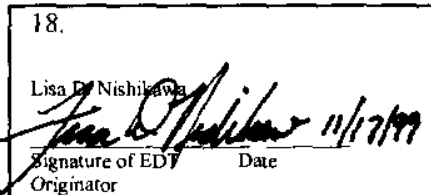 & $\begin{array}{l}19 . \\
\text { N/A } \\
\begin{array}{l}19 . \\
\text { Afthorized Representative } \\
\text { for Recevining Organization }\end{array}\end{array}$ & Date & Mike Wiemers & $\begin{array}{l}\text { 21. DOE APPROVAL (if required) } \\
\text { Ctrl. No. } \\
\text { [] Approved } \\
\text { ] Approved w/comments } \\
\text { [] Disapproved w/comments }\end{array}$ \\
\hline
\end{tabular}

BD-7400-172-2 (05/96) GEF097 


\title{
Memorandum of Understanding: Completion and Acceptance of the Spent Nuclear Fuel Project
}

\author{
L.D. Nishikawa \\ Fluor Daniel Hanford \\ Richland, WA 99352 \\ U.S. Department of Energy Contract DE-AC06-96RL13200 \\ EDT/ECN: $627119 \quad$ UC: 510 \\ Org Code: 2 F800 \\ Charge Code: 105568 \\ B\&R Code: $39 E W 70400$ \\ Total Pages: 1315 \\ PF $11-23-99$
}

Key Words: SNF, CVD, testing, acceptance, completion, operations, startup, construction

Abstract: This Memorandum of Understanding (MOU) is written to provide clear direction with respect to roles, responsibilities, obligations, and expectations of each organization identified. It functions as an agreement between the Operations, Construction projects and startup organizations within the spent Nuclear Fuels Project.

TRADEMARK DISCLAIMER. Reference herein to any specific commercial product, process, or service by trade name, trademark, manufacturer, or otherwise, does not necessarily constitute or imply its endorsement, recommendation, or favoring by the United States Government or any agency thereof or its contractors or subcontractors.

Printed in the United States of America. To obtain copies of this document, contact: Document Control Services, P.O. Box 950, Mailstop H6-08, Richland WA 99352, Phone (509) 372-2420; Fax (509) 376-4989.
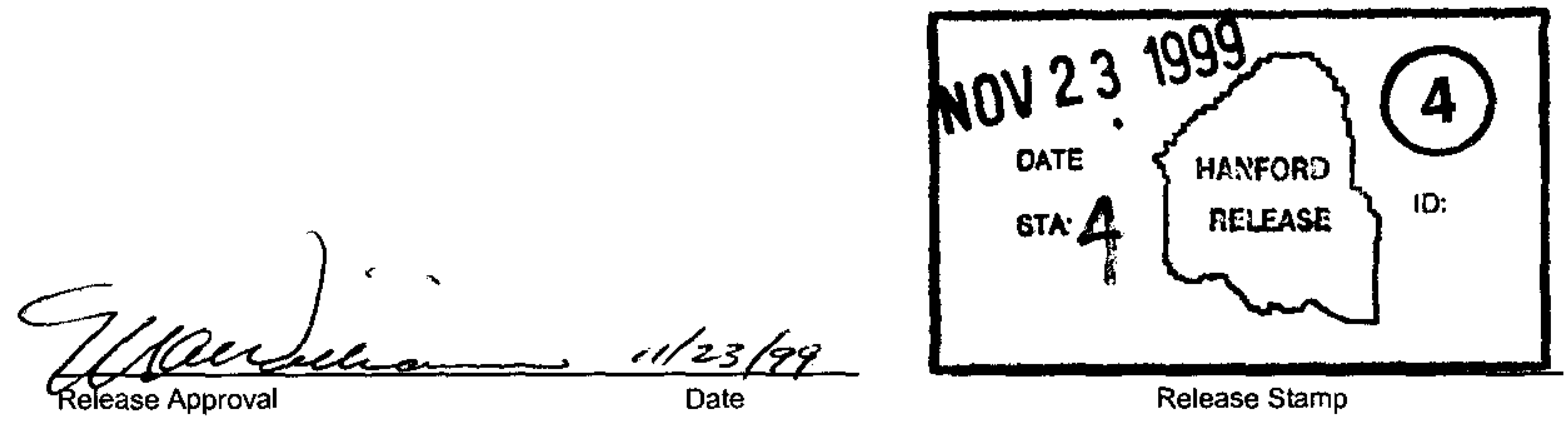

\section{Approved For Public Release}




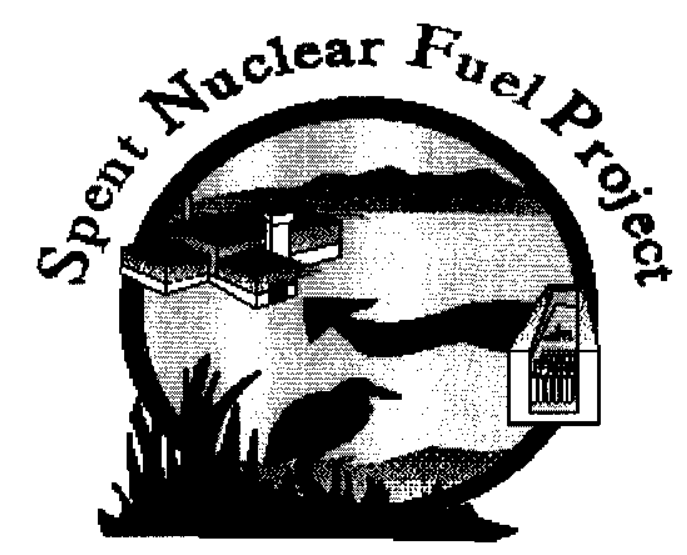

$$
\begin{gathered}
\text { SNF-5431 } \\
\text { Rev. } 0
\end{gathered}
$$

MEMORANDUM

OF

UNDERSTANDING

\title{
COMPLETION AND ACCEPTANCE
}

\author{
FOR THE
}

SPENT NUCLEAR FUEL PROJECT

November 10, 1999

REVISION 4 


\section{MEMORANDUM OF UNDERSTANDING COMPLETION AND ACCEPTANCE FOR THE SPENT NUCLEAR FUEL PROJECT}

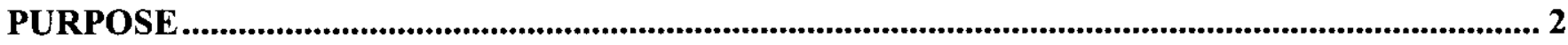

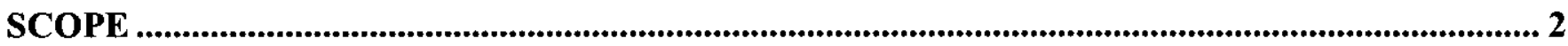

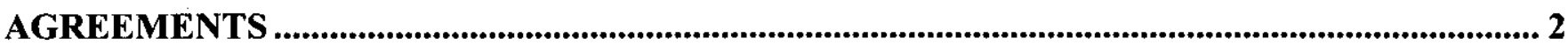

DEFINITIONS OF DOCUMENTS, FUNCTIONS, ROLES, AND RESPONSIBILITIES .............. 5

A. DOCUMENTS

1. Construction Completion Document (CCD) ………....................................................... 5

2. Official Acceptance of Construction $O A C)$.............................................................................. 6

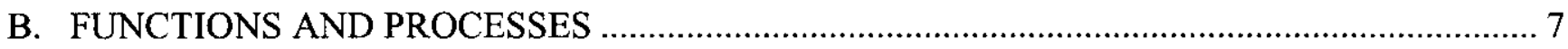

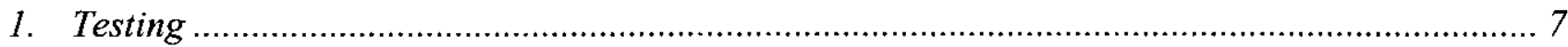

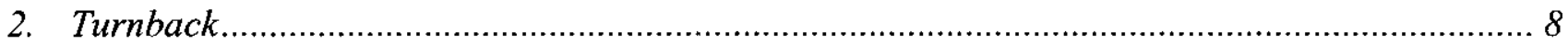

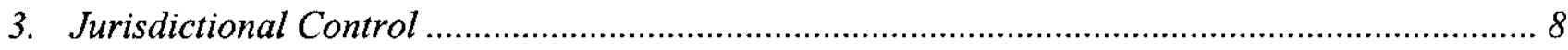

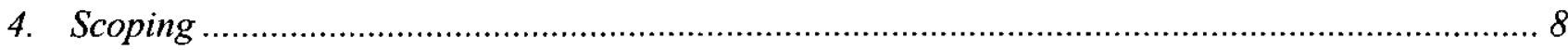

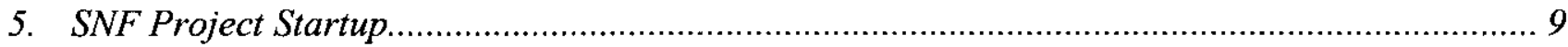

6. Design Verification Process .......................................................................................... 9

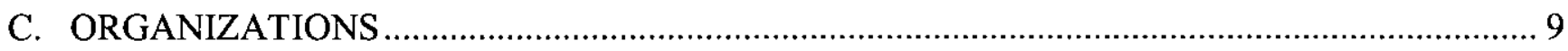

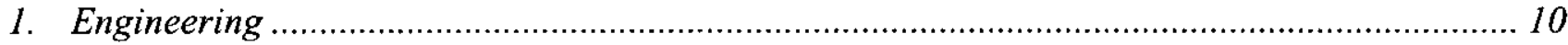

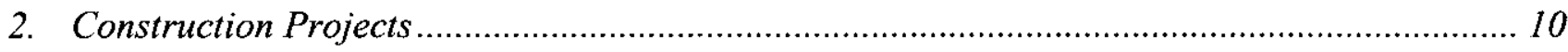

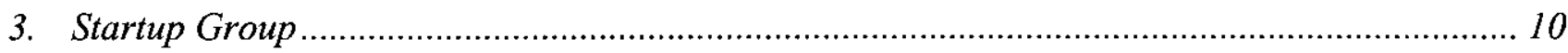

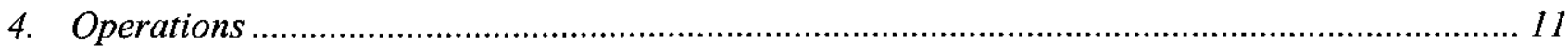

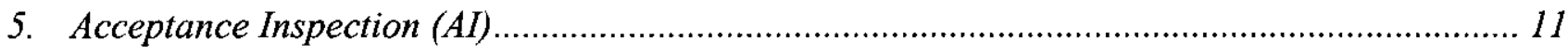

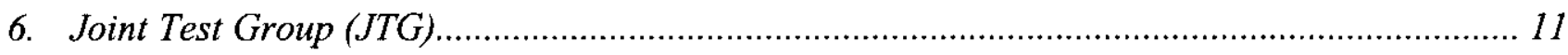

REFERENCES................................................................................................................................................. 12

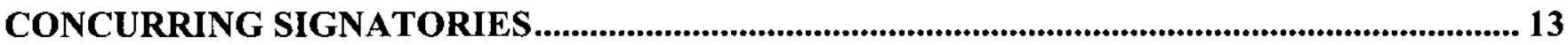




\section{MEMORANDUM OF UNDERSTANDING COMPLETION AND ACCEPTANCE FOR THE SPENT NUCLEAR FUEL PROJECT}

\section{Purpose}

This Memorandum of Understanding (MOU) is written to provide clear direction with respect to roles, responsibilities, obligations, and expectations of each organization identified. It functions as an agreement between the Operations, Construction Projects and Startup Organizations within the Spent Nuclear Fuels Project.

This MOU is written in support of the design, construction, startup, and turnover of completed structures, systems, and components (SSC) to Facility Operations of modifications and new construction within the Spent Nuclear Fuel Project.

This MOU will be implemented as written in support of the SNF Project Execution Plan, currently HNF-3552, Revision 0.A. This MOU is effective as of the date of final concurrence for this agreement. This MOU revision supersedes the earlier Memorandum of Agreement dated May 3, 1999.

\section{$\underline{\text { Scope }}$}

This MOU is applicable to the Canister Storage Building (CSB), Cold Vacuum Drying (CVD) Facility, new construction in $\mathrm{K}$ West and $\mathrm{K}$ East basins, and to modifications of structures, systems, and components in the $\mathrm{K}$ West and $\mathrm{K}$ East facilities.

Figure 1 of this MOU is a diagram that illustrates and delineates activities and responsibilities as discussed in this agreement document.

\section{Agreements}

The roles and responsibilities of the following organizations are agreed to by this MOU: SNF Startup, SNF Construction Projects, and SNF Operations.

1) Projects covered by HNF-PRO-572- The Canister Storage Building (CSB) and the KW Integrated Water Treatment System (IWTS) were both completed through $95 \%$ of physical construction and acceptance testing was initiated under HNF-PRO-572 prior to 7/15/99. These projects have been waived from HNF-PRO-2000 (Reference 12). These facilities will be turned over to SNF Operations for end user use following OACII.

2) Projects Covered by HNF-PRO-2000- HNF-PRO-2000 defines the phases and responsibilities during the duration of the construction phase and turnover to Operations for all projects which complete physical construction after 7/15/99. This includes Fuel Retrieval Systems (FRS), Cold Vacuum Drying (CVD), Cask-Transportation Facility Modifications (CTFM) and all future SNF projects, including all projects at the KE Facility.

3) For projects covered by HNF-PRO-2000, the SNF Construction Projects Manager retains accountability for all systems, structures and components (SSC) under his responsibility prior to CCDII. 


\section{MEMORANDUM OF UNDERSTANDING COMPLETION AND ACCEPTANCE FOR THE SPENT NUCLEAR FUEL PROJECT}

4) Startup and Operations Managers are responsible for performing the work safely and for following Integrated Environmental, Safety, and Health Management System (ISMS) principles and procedures while performing their testing functions. Construction Projects maintains safety oversight and overall responsibility until systems or projects are turned over to Operations following OACII or CCDII. The Startup and Operations Managers are accountable to the SNF Construction Projects Manager for the correct management of the SSC transferred to them for testing and will work closely with Construction Projects to resolve deficiencies encountered during testing.

5) SNF Construction Projects will assign custodial responsibility to the SNF Startup Manager to execute agreed-to portions of Acceptance Testing. SNF Startup provides matrixed support personnel to the specific subproject and receives funding from Construction Projects and Operations for their activities in acceptance and operational testing, respectively, as described in the Project Execution Plan. That support is further described in this MOU.

6) In greenfield projects (e.g. CSB and CVD) where no authorization basis or nuclear hazards exist, Construction Projects will oversee Acceptance Testing. For projects within an operating facility where an authorization basis is in effect and where nuclear hazards exist, SNF Operations will oversee Acceptance Testing. In greenfield projects, Construction Projects will coordinate and release all work activities, including testing, to address work conditions and interference issues. For activities within an operating facility, SNF Operations will coordinate and release all work activities.

7) SNF Construction Projects will assign custodial responsibility to the SNF Operations Manager for all operational testing. At this time, for financial expedience, the construction project will de-staff to a minimal number (never less than the sub-project manager, project engineer and design authority).

8) SNF Operations will have full control of the operational testing phase (OTPs), but will retain the ability to turn back the project, or parts of the project, to SNF Construction Projects if deficiencies are found which are within project scope. Deficiencies in the CSB Subproject (per HNF-PRO-572) will be appropriately funded and corrected at the time of finding.

9) At CCDII-A, a punchlist will be negotiated between the SNF Project Manager and the Operations Manager and concurred with by Engineering (DA). This punchlist identifies items and issues that will remain to be completed and also identifies the funding, schedule and precursor events (e.g. pre-ORR, Pre-start, Post-start) to which punchlist closure applies. All CCDII-A and subsequent activities will be performed in accordance with HNF-PRO-2000, Construction Program Execution Phase, as appended by negotiated agreements. Operational testing results will be reviewed and approved prior to CCDIIb. Note: The nature of the SNF Projects precludes demonstration of all performance requirements prior to ORR.

10) All parties to this agreement concur with their roles and responsibilities as defined in this MOU. 


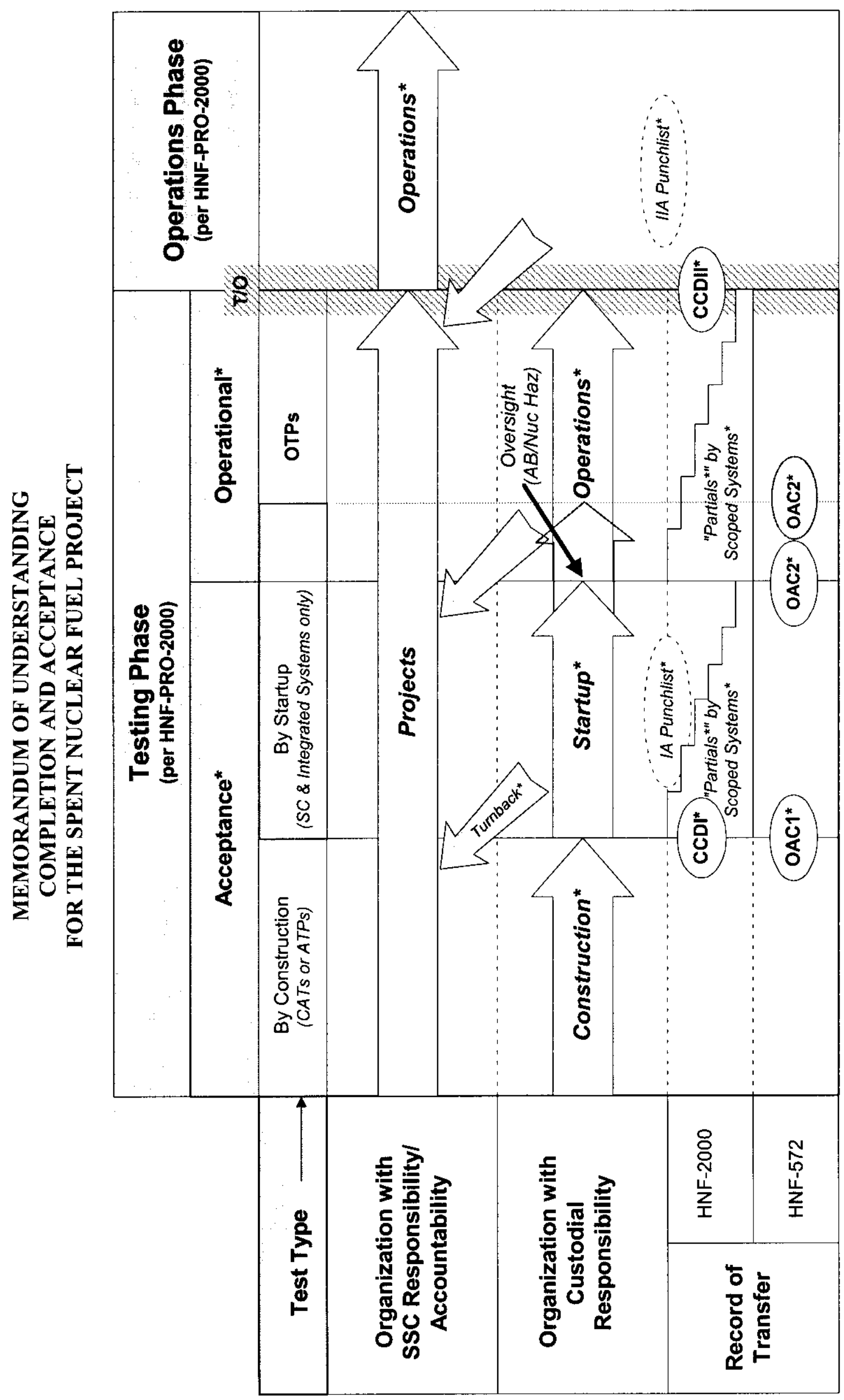

$\frac{5}{5}$

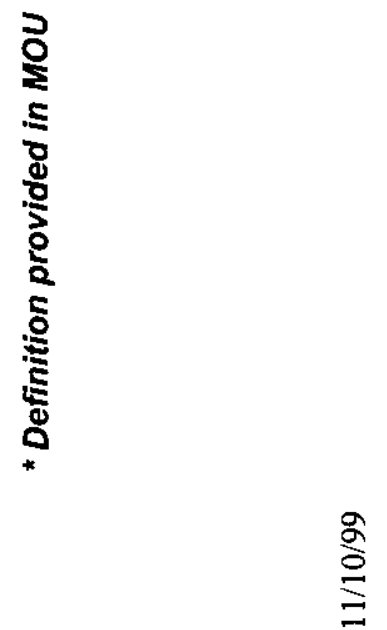




\section{MEMORANDUM OF UNDERSTANDING COMPLETION AND ACCEPTANCE FOR THE SPENT NUCLEAR FUEL PROJECT}

\section{Definitions of Documents, Functions, Roles, and Responsibilities}

The following definitions are provided for the purpose of understanding the roles and responsibilities agreed to in this MOU.

\section{A. DOCUMENTS}

1. Construction Completion Document (CCD)

(Applies to CVDF, FRS, CTFM, KW, and future work)

The CCD, which applies to sub-projects governed by HNF-PRO-2000, is defined by HNF-PRO-2000 as the record of transfer of completed facilities from construction to operations. A "Partial" CCD can be prepared to allow "functional" or system-by-system turnover until all phases are completed, at which time the CCD ("Total") is generated. Use of the CCD for minor construction activities is optional and will be determined jointly between the SNF Project Manager and the Operations Manager.

The two-part CCD form serves to document satisfactory completion of construction and the transfer of the completed facility/system to Operations.

Refer to Figure 1 for definition of the period between CCD I and CCD II.

\section{a) CCD Ia}

Section Ia of the CCD is defined, in accordance with HNF-PRO-2000, as follows:

"A Construction Completion Document (CCD) is initiated and processed as physical construction and construction acceptance testing approach substantial completion."

The following approvals are obtained for CCD Ia to constitute acceptance of completed construction, with any exceptions noted and attached as an exception list or punchlist:

- SNF Project Manager

- Acceptance Inspection

- RL Project Office

The date when CCD Ia is signed for those approvals is the construction completion date. For the SNF Project, the date of CCD Ia approval is also the date construction is complete and operational testing may commence.

(This corresponds to OAC I from HNF-PRO-572.)

\section{b) CCD Ib}

Section Ib of the CCD documents that the exception list or punchlist attached to CCD Ia has been completed, as described in HNF-PRO-2000. (This corresponds to OAC II from HNF-PRO-572.) 


\section{MEMORANDUM OF UNDERSTANDING COMPLETION AND ACCEPTANCE FOR THE SPENT NUCLEAR FUEL PROJECT}

\section{c) CCD II}

Section II of the CCD is defined, in accordance with HNF-PRO-2000, as follows:

"The final step in summary construction completion documentation occurs when operational testing has been completed and test results have been reviewed, analyzed, and approved by engineering. The major subcontractor or DynCorp (or other FDH assigned performer) is responsible for assuring that Sections IIa and IIb (when exceptions exist) of the CCD are initiated and processed. Signatures in Section Ila document Engineering approval of Operational Test results and Operations acceptance of the completed functional system/project."

HNF-PRO-2000 makes provisions for a post turnover exception or punchlist which allows formal turnover to proceed based on negotiated action items identified to close out the remaining Construction Projects' responsibilities:

"In some cases, functionality is demonstrated while exception items are still open. Section Ila of the CCD may be completed with an attached exception list. Exceptions (for formal construction projects) are tracked to completion and documented as complete (on the exception list) by the FDH-QAAcceptance Inspection (AI) group. Signatures in Section IIb document that Section IIa exception items have been completed."

\section{Official Acceptance of Construction (OAC)} (Applies to CSB and $K W$-IWTS)

The official acceptance of construction is the record of transfer of completed facilities from construction to operations personnel for all projects except minor projects.

OAC is completed when the project construction phase is approximately $95 \%$ complete. An official project punchlist is developed by the AI which is then completed by construction. When OAC I is prepared, all open punchlist items are transferred to an exceptions list. If no exceptions exist, then OAC I and OAC II may both be signed. The following signatures are required for OAC I:

User/Sponsor (Project Manager)

Acceptance Inspector

RL Project Office

Section II of OAC (OAC II) must be signed prior to the User/Sponsor (Operations) taking beneficial use. All noted exceptions from OAC I are completed and acceptance testing has been completed. The User/Sponsor accepts responsibility for the operation and maintenance of the complete facility/system by signing Section II and accepts responsibility for any new deficiencies identified after Section II has been approved. The User/Sponsor (Operations) may take conditional beneficial use prior to all exceptions from OAC I being completed. However, Projects are still required to complete the exceptions. The following signatures are required for $\mathrm{OAC} \mathrm{II:}$

User/Sponsor (Operations Manager)

Acceptance Inspector

RL Project Office 


\section{MEMORANDUM OF UNDERSTANDING \\ COMPLETION AND ACCEPTANCE \\ FOR THE SPENT NUCLEAR FUEL PROJECT}

Section III of OAC (OAC III) is completed when Section I and Section II have been completed and exceptions are closed. If exceptions are not closed, the project must arrange for correction of any project-related deficiencies and identify and obtain funds, and accrue funds for any outstanding exceptions and coordinate resolution of the exceptions the following signatures are required:

User/Sponsor (Operations Manager)

Acceptance Inspector

RL Project Office

Normally, the OAC signatures all occur within 90 days after the Construction Completion date (OAC I). Special circumstances may allow additional time.

\section{B. FUNCTIONS AND PROCESSES}

\section{Testing}

Testing as discussed in this MOU is the process for demonstrating that an SSC is constructed, installed, and functions as designed. Within this MOU, per HNF-PRO-2000, there are two phases of testing, Construction Acceptance Testing (referred to as Acceptance Testing) and Operational Testing.

\section{a) Acceptance Testing Performed by Construction Projects}

The first part of the construction acceptance phase of testing is performed by Construction Projects and involves those test activities designed to test system components and document that physical construction has been completed in accordance with approved engineering and design documents. It may include energized component testing in support of preparation for Operational Testing. It is performed prior to Operational Testing.

Per HNF-PRO-2000, Acceptance testing is usually performed in accordance with approved Acceptance Test Procedures. Typical construction acceptance testing activities (depending on the particular system being tested) include, visual inspections, continuity checks, verification of equipment rotation, filling and flushing, hydrostatic pressure testing, instrument and control calibration, and loop checks. Results from construction acceptance testing shall be evaluated (by engineering and design) to ensure that requirements have been satisfied.

CCD Ia is signed upon completion of the this portion of the Acceptance Testing phase.

\section{b) Acceptance Testing Performed by Startup}

The second part of the construction acceptance phase of testing is an integration of traditional component acceptance testing with the system testing requirements of traditional operational test procedures (OTPs). For example, components in a system can be tested as part of an entire system. This testing ensures that the equipment system components function properly but does not verify that the system will perform its design function. (e.g. the PCM washing machine rotates and the sprays work, however it is not yet confirmed that the machine will clean fuel to specification.) 


\section{MEMORANDUM OF UNDERSTANDING \\ COMPLETION AND ACCEPTANCE \\ FOR THE SPENT NUCLEAR FUEL PROJECT}

Pre-operational acceptance testing is SSC functional testing in preparation for turnover to Operations for the Operational Testing phase. This portion of Acceptance Testing is completed by SNF Startup, under the direction of SNF Construction Projects with support from Operations as needed.

\section{c) Operational Testing}

The final phase of testing is Operational Testing. Per HNF-PRO-2000, Operational Testing is designed to verify and document that construction complete systems and projects meet specified performance requirements. It is performed after construction acceptance testing completion. In this testing phase, custody of an SSC, or a portion of it, is turned over to SNF Operations. In this phase of testing, SNF Operations verifies that entire subsystems and systems meet the applicable performance criteria previously established for the affected Project SSC. The Engineering Organization (Design Authority, per PRO 1819) is responsible for formal confirmation that the Project functional requirements for the affected SSCs have been met. SNF Startup provides matrix support to Operations to assist in performing these tests. This testing also serves the purpose of validating procedures and training personnel in hands-on use of the SSC. The Operational Testing phase can begin once acceptance testing is complete.

\section{Turnback}

Turnback is the process of returning custody of an SSC to Construction Projects Management that has been previously released to Startup or to Operations for Testing (per HNF-PRO-2000). Custodial responsibility of the SSC is transferred to Construction Projects Management on a temporary basis for completion of Punchlist items, corrective action, or other authorized action. Actions taken by Construction Projects Management during temporary jurisdictional control and custody are subject to that organization's procedures.

\section{Jurisdictional Control}

The process to transition SNF projects from Construction to Startup or Operations consists of assigning custodial responsibility to the organization performing acceptance testing or operational testing. The ultimate responsibility for the SSC and for facility/system safety rests with the SNF Construction Project Manager during all phases prior to CCD-II (or OAC-III) and with Operations following CCD-II (or OAC-III). Turn back of systems from the Startup Group to Construction Projects to correct deficiencies will be as described in OP-10-026.

If the project is completed with exceptions, Operations and the SNF Construction Projects Manager can implement conditional acceptance for beneficial use; however, Construction Projects management retains responsibility for the completion of the negotiated exceptions.

\section{Scoping}

Scoping is the process of defining "functional system" test boundaries and the components within those boundaries that when taken together form a logical group that allows meaningful testing to be performed, in accordance with SNF Project Administrative Procedure OP-10-005 and HNF-PRO-2000, Paragraph 3.4.2.1. These requirements are accomplished by marking piping and instrumentation 


\section{MEMORANDUM OF UNDERSTANDING \\ COMPLETION AND ACCEPTANCE \\ FOR THE SPENT NUCLEAR FUEL PROJECT}

diagrams (P\&IDs), electrical single line drawings, elementary diagrams, and other design engineering documents. The scoping process identifies specific mechanical, electrical, and instrumentation boundaries that are related to a single system or subsystem. Note that the "functional system" breakdown may or may not correspond to the permanent plant system breakdown.

\section{SNF Project Startup}

SNF Project startup involves the controlled and managed process by the Startup organization for systemlevel acceptance testing. Testing activities are conducted in accordance with HNF-PRO-286, HNFPRO-1819, and SNF OP-10 series.

\section{Design Verification Process}

Testing is a key element of design verification and validation, which is dictated by HNF-PRO-1819 and other SNF Project requirements documents. The SNF Design Verification Process is documented in EN-6-027 and defined as "a system engineering process, which is used to ensure:

a. A design is technically adequate;

b. Design inputs have been evaluated and verified for their impact on the design (both final design and subsequent changes/revisions);

c. The design meets the applicable requirements for environmental, quality, safety, and performance at a reasonable cost; and

d. Operations requirements are met.

Design verification ensures that mission objectives are satisfied because the system requirements are used as the criteria during verification. Requirement verification methods include, but not be limited to 1) Analysis; 2) Review; 3) Testing; and, 4) Inspection.

Per EN-6-027 graded verification approach is be used so that the rigor with which methods of verification are applied is appropriate, as a minimum to the:
a. Cost,
b. Complexity,
c. Importance to safety,
d. Environment, and
e. Risk of the project.

Detailed guidelines for developing this graded approach are provided in EN-6-027. The SNF Test program and Testing strategy will be executed in conformance with this graded approach to design verification and validation.

\section{ORGANIZATIONS}




\section{MEMORANDUM OF UNDERST ANDING \\ COMPLETION AND ACCEPTANCE \\ FOR THE SPENT NUCLEAR FUEL PROJECT}

\section{Engineering}

Engineering as discussed in this MOU is the organization that identifies and develops the design for construction of the CSB and CVD facilities and modification or renovation of KE \& KW Basin SSCs. Engineering is responsible for identifying acceptance criteria for testing and for resolution of design related issues identified through testing.

Each SSC has a single appointed Design Authority. The Design Authority, in accordance with HNFPRO-2000 and HNF-PRO-1819, has the following responsibilities:

- Maintaining design baseline, including approving modifications

- Establishing design requirements

- Approving design criteria, including changes

- Ensuring that appropriate design criteria are provided to the design organization

- Approving engineering work plans

- Specifying acceptance parameters, inspection or test requirements

- Approving test results

- Approving all design documents

Additionally, engineering is responsible for the resolution of design-related issues and concerns raised by employees and third party identifiers. Resolved issues will be forwarded to the SNF Construction Project Manager within one working day of resolution for adjudication and incorporation, where required, into the project scope through fiscal change processes.

\section{Construction Projects}

SNF Construction Projects plans, procures, and implements activities for completion of a constructed facility and construction acceptance testing. As construction is completed, the Construction Projects releases custodial responsibility of the scoped boundary to Startup for remaining acceptance tests.

Construction Projects management is responsible for the SSC-related scope of work, SSC-related cost, and SSC-related control of schedule prior to and until approval of Section Ila of the CCD or OAC-III (see Figure 1). The Operations organization funds operational testing and maintains control over the schedule for this activity.

Upon completion of the subproject construction and construction acceptance testing, custodial responsibility or final turnover of selected SSCs from Projects to Operations will occur as defined in this MOU.

For K Basins subprojects, Startup works with the Operations work control organization in the development and implementation of work packages to support Operational Testing activities.

\section{Startup Group}

Startup accepts custodial responsibility of the SSC for performance of agreed-to, system-level acceptance tests, including responsibility for preventive maintenance during this period through completion of these tests. Construction forces will be utilized to support Startup in implementation of 


\section{MEMORANDUM OF UNDERSTANDING \\ COMPLETION AND ACCEPTANCE \\ FOR THE SPENT NUCLEAR FUEL PROJECT}

these functions. Operations personnel will be utilized during testing as a form of training to develop or improve job performance as conditions allow. This does not preclude the Operations and Project Manager from negotiating a phased turnover that is appropriately documented.

Startup is responsible for performing portions of the Acceptance Testing or Operational Testing scope of work as an organization matrixed to the SNF Construction Projects Manager for the specific subproject or Operations as applicable. Startup provides scoped test boundaries to SNF Construction Projects to facilitate timely testing. Startup prepares test packages for acceptance tests performed by Startup.

Startup assumes responsibility for corrective action required as a result of testing error or omission during implementation of acceptance tests performed by Startup. Corrective action required as a result of a test deficiency identified by an equipment failure, inadequate design, or improper installation remains the responsibility of SNF Construction Projects.

Following CCD I (or OAC I) and until the start of Operational Testing, Startup assumes custodial responsibility for execution of specified acceptance tests upon proper release of individual SSCs from the subproject. Startup may return custodial responsibility of an SSC to the subproject for the purposes of completing Punchlist items, corrective actions, or other authorized actions per OP-10-026.

\section{Operations}

Operations assumes Project SSC custodial responsibility for Operational Testing. Operations provides qualified or provisionally-qualified personnel through the Shift Manager to perform Operational Test activities (and support to Acceptance Testing wherever possible) in accordance with approved procedures. The assignment of Operations personnel is governed by the requirements and accepted practices of the work integration process. Operations may return jurisdictional control of an SSC to the Construction Projects group of the applicable subproject for the purposes of correcting deficiencies found to be within Construction Project scope or other authorized action.

\section{Acceptance Inspection (AI)}

The Acceptance Inspection function provides independent construction inspection/testing and source inspection/testing of construction workmanship, materials, and equipment for conformance to approved drawings and specification, IAW HNF-PRO-2000. The Quality Inspection Services inspectors organization (Acceptance Inspection (AI)/Title III) representative(s) develop(s) the official SNF Project Punchlist following a project walkthrough coordinated by Manager of SNF Construction Projects, in accordance with HNF-PRO-2000 (or HNF-PRO-572 as appropriate).

The AI is involved from the completion of construction (CCD Ia) through completion of project acceptance (CCDIIb). The AI performs inspections to determine project acceptability, verifies acceptability, and signs for Punchlist items as completed.

The AI shares no responsibility for this MOU.

\section{Joint Test Group (JTG)}




\section{MEMORANDUM OF UNDERSTANDING \\ COMPLETION AND ACCEPTANCE \\ FOR THE SPENT NUCLEAR FUEL PROJECT}

The ITG is defined by OP-10-003 as an eight (8) member board of representatives who review the test documents prepared by the Startup organization and provide approval recommendation to the Startup manager. Minimum scope of review is system-level Acceptance Test procedures, System-level Test Summary Reports, Test Procedure Change Notices, and Test Specifications.

\section{REFERENCES}

1) DE\&SH Internal Memo 2T011-SU-I-98-004, Memorandum of Agreement for Transition from Construction Activities to Startup Testing; dated December 2, 1997.

2) SNF Project Memorandum of Understanding, Completion and Acceptance for the Spent Nuclear Fuel Project, dated April 7, 1999.

Project Hanford Management System Plans and Procedures:

3) HNF-3552, Spent Nuclear Fuels (SNF) Project Execution Plan.

4) HNF-PRO-286, Test Control.

5) (Cancelled)HNF-PRO-572, Project Acceptance and Closeout.

6) HNF-PRO-1819, PHMC Engineering Requirements.

7) HNF-PRO-2000, Construction Program Execution Phase.

SNF Project Administrative Procedures (APs):

8) OP-10-003, Startup Joint Test Group

9) OP-10-005, Startup System and Subsystem Scoping

10) OP-10-026, Turnback of Systems, Structures and Components (SSC)

11) EN-6-027, Design Verification Process

12) Waiver of CSB and KW-IWTS from HNF-PRO-2000 


\section{MEMORANDUM OF UNDERSTANDING \\ COMPLETION AND ACCEPTANCE \\ FOR THE \\ SPENT NUCLEAR FUEL PROJECT}

\section{CONCURRING SIGNATORIES}

$\frac{\operatorname{dla} w \omega .}{D . \text { W. Siddoway }}$

SNF Project Manager

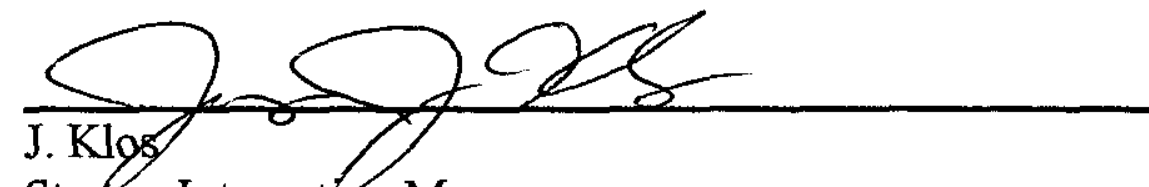

Startup Integration Manager

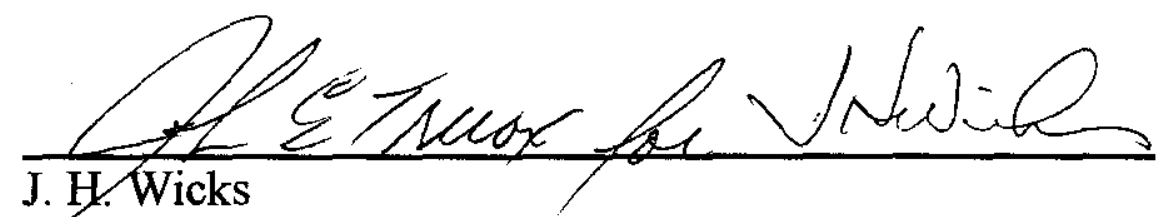

$\frac{11 / 10 / 29}{\text { Date }}$

$\frac{11-16-99}{\text { Date }}$

thanager of Operations

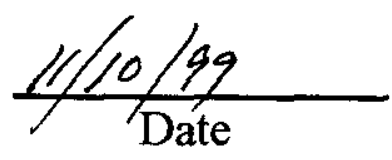

13 of 13




\section{DISTRIBUTION SHEET}

To

Distribution

Project Title/Work Order

SNF-5431, Memorandum of Understanding: Completion and Acceptance for

the Spent Nuclear Fuel Project

\begin{tabular}{|l}
\hline \\
\hline Dean Siddoway \\
\hline Jim Wickes \\
\hline Jim Klos \\
\hline Bill Miller \\
\hline CVD Library \\
\hline SNF Project Files \\
\hline SNF Startup Library \\
\hline CVD Satellite Library
\end{tabular}

From

LD Nishikawa, SNF-CVD

\section{ame}

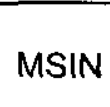

$\times 3-85$

$\times 3-71$

X3-71

R3 - 11

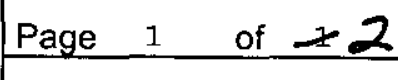

Date $11 / 17 / 99$

EDT No. 627119

ECN No. N/A
Attach./

Appendix

Only

EDT/ECN

Only 
To: Distribution

No

Date:

99-SNF/MJW-027

From

M. J. Wiemers

cc: $\quad$ MJW lb/File

SNF Proiect Files
Telephone:

$376-9516$

\section{Subject: $\quad$ MEMORANDUM OF UNDERSTANDING: COMPLETION AND ACCEPTANCE FOR THE SPENT NUCLEAR FUEL PROJECT}

Attached for your information is the latest revision of the Memorandum of Understanding (MOU) for Completion and Acceptance for the Spent Nuclear Fuel Project, Revision 4 (SNF-5431, Rev. 0). The MOU has been entered into the SNF Project File under EDT 627119. Please note that the MOU routed for signature was Revision $3 E$ dated 11/10/99, and was issued with no changes under a final revision number 4 . Also, for purposes of record keeping, two signature sheets were combined to create a single signature sheet.

This MOU provides clear direction with respect to roles, responsibilities, obligations, and expectations of each organization identified in the MOU. It functions as an agreement between the Operations, Construction Projects, and Startup Organizations within the Spent Nuclear Fuel Project.

For further information, please contact me at 376-9516.

$\operatorname{ldn} / \mathrm{jj}$

Attachment 